\title{
The Production of Zeolite Y Catalyst From Palm Kernel Shell for Fluid Catalytic Cracking Unit
}

\author{
Angela Mamudu $\left(\mathbb{D},{ }^{1}\right.$ Moses Emetere $\mathbb{D}^{D},{ }^{2}$ Felix Ishola ${ }^{(D)},{ }^{3}$ and Dorcas Lawal ${ }^{1}$ \\ ${ }^{1}$ Department of Chemical Engineering, Covenant University, Ota, Nigeria \\ ${ }^{2}$ Department of Physics, Covenant University, Ota, Nigeria \\ ${ }^{3}$ Department of Mechanical Engineering, Covenant University, Ota, Nigeria \\ Correspondence should be addressed to Angela Mamudu; angela.mamudu@covenantuniversity.edu.ng
}

Received 15 June 2020; Revised 15 September 2020; Accepted 17 March 2021; Published 31 March 2021

Academic Editor: Ho SoonMin

Copyright (C) 2021 Angela Mamudu et al. This is an open access article distributed under the Creative Commons Attribution License, which permits unrestricted use, distribution, and reproduction in any medium, provided the original work is properly cited.

\begin{abstract}
Exorbitant costs of fluid catalytic cracking unit (FCCU) catalysts coupled with their ever-increasing demand have led researchers to develop alternative materials from indigenous sources. In this study, the zeolite Y component of the FCCU catalyst was synthesized from palm kernel shells. Leaching was carried out with the aid of citric acid to remove impurities. The synthesis process was done using alkaline hydrothermal treatment while varying reagent concentration and reaction time. The resultant products were characterized using XRF, XRD, FTIR, BET, and SEM analysis. The XRD and XRF showed a high silicate content level, while an $85 \%$ reduction in iron oxide impurities was observed after leaching. The process carried out at a duration of 9 hours, a temperature of $80^{\circ} \mathrm{C}$ with a $\mathrm{NaOH}$ molarity strength of $2 \mathrm{~mol} / \mathrm{L}$, had the highest $\mathrm{SiO} 2$ and $\mathrm{Si} / \mathrm{Al}$ ratio value. A spongy, porous zeolite crystal was formed with the presence of hydroxyls in its sodalite cage. All samples had a combination of types II \& I adsorption isotherms, Si/Al ratio of $2-5$, and specific surface area within $80-260 \mathrm{~m}^{2} / \mathrm{g}$, which indicates the presence of intermediate mesostructured Zeolite Y catalyst. Synthesized zeolite Y showed a more significant gap in its structural formation as the addition of $\mathrm{NaOH}$ decreased the grain size by $14.3 \%$. FTIR highlighted the significant functional groups present in the novel compound, which, when compared to previous works, proves its suitability.
\end{abstract}

\section{Introduction}

Petroleum refining is a process through which crude oil is converted into useful products [1]. Although it has many distinct units, the conversion and separation units always play significant roles [2]. The fluid catalytic cracking unit (FFCU), which falls under the conversion group, remains an indispensable unit operating in refineries. It converts about $40 \%$ of the heavy residues gotten from both vacuum and atmospheric distillation into lighter and more useful products with higher octane values $[3,4]$. According to Vogt and Weckhuysen [5]; the heavy hydrocarbon molecules (majorly gas oil) preheated at about $149^{\circ} \mathrm{C}$ are charged as a feedstock into a catalyst riser containing particles of powdered catalyst that are fluidized by the hydrocarbon vapors. Cracking occurs within 2-4 seconds in the riser, where the heavy molecules are broken down into lighter and shorter chain molecules at $1 \mathrm{~atm}$ with a temperature range of $520^{\circ} \mathrm{C}-550^{\circ} \mathrm{C}$. Separation occurs in the distillation column while the catalyst particles are re-generated.

One of the significant achievements that have contributed to the ever-growing popularity of the FCCU has been the introduction of Zeolite catalysts. Zeolites are hydrated alumina silicate materials made from inter-linked tetrahedral of alumina $\left(\mathrm{AlO}_{4}\right)$ and silica $\left(\mathrm{SiO}_{4}\right) .130$ out of 840 catalysts used in industrial applications are based on zeolites, and the FCCU in petroleum refineries utilizes over $61 \%$ of these zeolite-based catalysts. The zeolite component makes up 10-50 wt.\% of the catalyst and provides activity, stability, and selectivity. Zeolites are produced both synthetically and naturally, but most of the zeolites used in the FCCU are synthetically produced. Synthetic zeolite has fewer 
impurities and has a more uniform pore size than its natural counterparts [6]. However, various types of synthetic zeolite's major catalyst exist. Zeolite Y from the faujasite family has continued to gain worldwide recognition, mainly due to its inherent properties-acidity, thermal stability, and the increase in gasoline yield [7].

Zeolites have a substantial global consumption of nearly 4 million metric tons per annum, while commercial catalyst keeps experiencing unprecedented inflation [8]. The chemicals used in the conventional synthesis of commercial zeolites are very costly, leading to high zeolite production costs [9]. Also, most of the natural zeolites are gotten through mining, and frequent mining can result in environmental degradation. Therefore, there is a need to provide alternate materials from indigenous sources that are less expensive and environmentally friendly. Researchers in the past have tried to investigate the suitability of various indigenous sources (fly ash, natural clays, rice husks, oil palm ash) for zeolite Y synthesis. Results show a reasonable amount of silicon compounds present in them, a prerequisite for zeolite synthesis [10]. Ariffin [11] proved that silica and alumina are significant components in producing zeolites from oil palm ash. Faizul et al. [12] ascertained the effectiveness of citric acid used in the leaching treatment to extract silica from oil palm ash.

Although various research has been carried out on palm kernel shell's total utilization, none is channeled to the fluid catalytic cracking unit. Hence, this study ascertains Zeolite Y catalyst production from palm kernel shells via pre-treatment, hydrothermal, and various characterization processes. Pretreatment involves ashing, which extracts silica contents from the feed while leaching further removes metallic oxide impurities. The effects of varying reagent concentration and reaction time during the hydrothermal process were also observed for optimum production. Physicochemical properties of selected samples were analyzed via X-ray Fluorescence (XRF), X-ray Diffraction (XRD), Brunaurer-Emmett Teller (BET), Scanning Election Microscope (SEM), and Fourier Transform Infrared Spectroscopy (FTIR) to determine its suitability for use in the fluid catalytic cracking unit of a refinery.

1.1. Palm Kernel Shells. Palm kernel shells (PKS) are waste products from oil palm processing [13]. They are generally the remains after palm kernel nuts are crushed in oil palm mills. A combination of Tenera and Dura (oil palm variety) was used in this study since it was difficult to separate the two. Although the literature on using palm kernel shells in zeolite synthesis has not been extensive, its maximization in other areas has been highlighted. Palm kernel shells can be used to produce biomass briquettes, activated carbon, and secondary fuel for boilers [14, 15]. Therefore, using palm kernel shells as a starting material in zeolite production is driven by low cost and availability in large quantities. The process will also serve as a means of effective utilization of waste.

Generally, the synthesis of solid-state materials can either take place in a solid-state or the presence of a liquid solvent [16]. The solid-state method usually requires a high temperature above $300^{\circ} \mathrm{C}$ to overcome difficulties transporting the reactants to the reaction sites. Synthesis of zeolite $\mathrm{Y}$ catalyst occurs via molecular transport in the liquid phase since it is much easier $\left(>300^{\circ} \mathrm{C}\right)$. The alkaline hydrothermal approach was adopted for this process to ensure the crystallization of molecular sieve zeolite. The process was achieved by mixing an aluminate and silicate source to form amorphous aluminosilicate gel. The crystallization process involves nucleation and crystal growth. Nucleation involves creating the smallest entity, which can be recognized as having a crystalline atomic structure. Simultaneously, crystal growth ensures the nuclei's evolution to larger macroscopic sizes [17].

The Zeolite $\mathrm{Y}$ catalyst prices in the Fluid Catalytic Cracking unit generally vary based on the Si/Al ratio. Presently top producers/suppliers (Jiangsu AFNANO Materials Tech Co., Ltd and Xiamen Futt Laboratory Materials Limited) sell 100-499 grams (US\$ 0.26-0.30); 500-999 grams (the US $\$ 0.26$ ) and $\geq 1000$ grams (the US \$0.26) [18]. All works carried out on the synthesis of Zeolite Y catalyst from palm kernel shell ash, fly ash, or industrial clays has been carried out on a laboratory scale to prove the feasibility of the process $[11,19-26]$ and [27].

\section{Material and Methods}

The methods adopted to accomplish the research focus are presented in the flowchart below (Figure 1).

2.1. Preparation of Raw Materials. The Palm Kernel Shells used were sourced from two locations (Ikere and Sekona District) in Ogun State, Nigeria. These materials were first washed to remove sand and other dirt. Afterward, they were sundried for five days to remove moisture. The dried shells were then crushed with a mechanical grinder to a particle size of 75-100 micrometers. Calcination of the crushed palm kernel shells was carried out in a Barnstead box-type hightemperature muffle furnace (F46118) at a temperature of $800^{\circ} \mathrm{C}$ for three hours to yield palm ash. F46118 operates with 240 volts, 40 amps while the maximum ramp rates for heat up are: $100^{\circ} \mathrm{C}$ per minute from $25^{\circ} \mathrm{C}$ to $1000^{\circ} \mathrm{C}$ and $15^{\circ} \mathrm{C}$ per minute from $1000^{\circ} \mathrm{C}$ to $1700^{\circ} \mathrm{C}$.

2.2. Leaching Process. The leaching process was carried out using the method reported by Faizul et al. [12]. This method replaced the conventional use of strong acids in leaching treatment with citric acid because of its environmentally friendly nature. The leaching treatment was carried out to remove metallic oxide impurities present in the PKSA so that more of the silica can be utilized for zeolite synthesis. $20 \mathrm{~g}$ of PKSA was put into a $500 \mathrm{ml}$ citric acid solution in a beaker, placed on the hot plate (temperature set at $70^{\circ} \mathrm{C}$ ) for 60 minutes. The PKSA was rinsed with distilled water at room temperature to remove citric acid content from the ash. Drying was carried out at a temperature of about $70^{\circ} \mathrm{C}$ for 55 minutes in the oven and combustion at $800^{\circ} \mathrm{C}$ for 30 minutes in the tube furnace. The chemical composition of the treated ash was determined by X-ray fluorescence spectroscopy (XRF). 


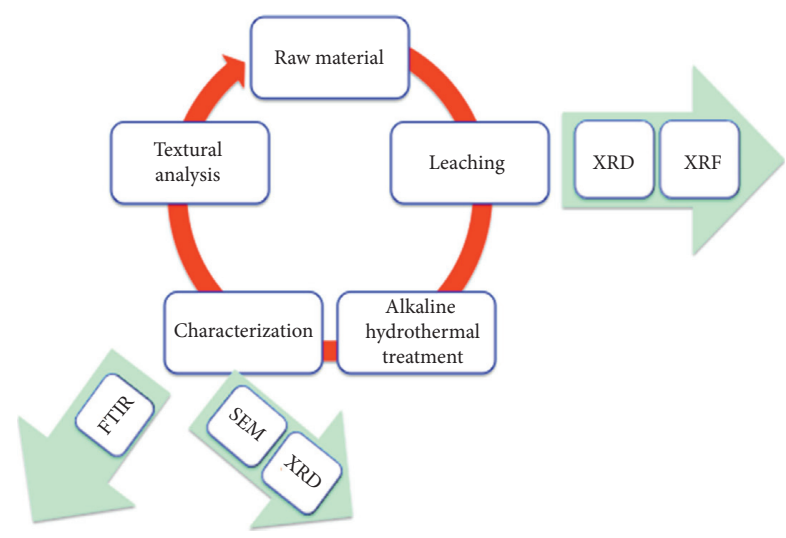

FIGURE 1: Flow chart for process methods.

2.3. Alkaline Hydrothermal Treatment. The hydrothermaltreatment procedure was adopted from Faizul et al. [21] and Faizul and Abdullah [20] with some modifications. The alkaline hydrothermal treatment is an essential one because it mimics the set conditions of zeolite minerals' formation in nature [28]. Different $\mathrm{NaOH}$ concentrations (1M, 2M, and $3 \mathrm{M}$ ) were reacted with a known weight of treated PKSA with a ratio of $1: 0.3$. The mixture was then aged and crystallized with mechanical agitation placed in a water bath. The synthesis was carried out at a temperature of $80^{\circ} \mathrm{C}$ and at different reaction times ( 5,7 , and 9 hours). Reliable products obtained from the alkaline hydrothermal treatment were recovered by filtration and washed with distilled water. Recovered products were then dried at $70^{\circ} \mathrm{C}$ for 30 minutes and cooled in a desiccator before product characterizationXRD, FTIR, XRF, BET, and SEM analysis.

2.4. Product Characterization. XRF remains a non-destructive analytical technique carried out on the raw palm kernel ash, treated palm kernel ash, and synthesized product to determine the materials' elemental composition. The XRF was carried out using model TEFA ORTE, copper K-alpha with a wavelength of 1.550 radiation, operating at $40 \mathrm{kV}$ (kilovolts) and $25 \mathrm{~mA}$ (milliampere). X-Ray Diffractometer (XRD) analysis is generally used to study the crystallographic structure, chemical composition, and physical properties of materials. The calcined PKSA were analyzed using a Rigaku Rotaflex 200B diffractometer equipped with copper K-alpha with a wavelength of 1.54056 radiation. It was operated at $40 \mathrm{kV}$ (kilovolts) and $40 \mathrm{~mA}$ (milliampere). XRF identifies elemental percentages of crystallinity in a material. SEM was done with model Schottky Field Emission JSM $-760^{\circ} \mathrm{F}$ on the treated palm ash and synthesized product to determine the microstructures. However, the microstructure reveals its morphology, composition, and particle surface crystallography information. The FTIR analysis was carried out on the product to identify any form of organic, polymeric, and inorganic materials present.

2.5. Textural Properties. The synthesized zeolite's efficiency from palm kernel shell ash (PKSA) depends mainly on its textural properties, including the specific surface area and pore size distribution. During the production of PKSA, two steps are involved-the raw shells' carbonization to enrich the carbon content and the carbonized shells' activation. The activation process frees deposited tars and decomposed products from initially blocked pores. Therefore, the level of porosity achieved mainly depends on the mechanism of carbon removal, which is chiefly controlled by the activating conditions (reagent concentration and reaction time). In this study, Physisorption of nitrogen $(77 \mathrm{k})$ at relatively low pressure $\left(10^{-6} \mathrm{P} / \mathrm{Po}\right)$ for all active carbon is employed. The micropore volume was measured using the DubininRadushkevich (DR) theory, associated with enhanced adsorbent-adsorbate interactions [29]. The adsorption isotherms were interpreted by applying the modified BET (Brunauer-Emmett-Teller) method.

\section{Results and Discussion}

3.1. Characterization of PKSA and Treated PKSA. The initial and treated PKSA were both characterized using X-ray fluorescence to compare the percentage of impurities in both samples and determine the leaching treatment's effectiveness. Table 1 shows the weight percentage of significant constituents found in both crude and treated PKSA.

Generally, variation in chemical composition can be traced to geographical location and soil type [30]. It is observed from Table 1, row 4 above, that there has been a significant increase in the silica content of the oil palm ash and a reduction (85\%) in the metallic oxides (impurities) after the leaching treatment, which proves that the leaching treatment was effective. The citric acid contains carboxyl groups that behave as a chelating agent, reacting with metallic ions to form stable complexes, which resulted in the removal of metallic ions [12]. Table 1 also affirms the findings of Iskander et al. [31] that the desorption pattern of the metallic impurities varies in the zeolite.

\subsection{Characterization of Synthesized Zeolite}

3.2.1. XRF Analysis. As stated earlier, the synthesis of zeolite $\mathrm{Y}$ from the oil palm ash by a hydrothermal treatment was carried out at different $\mathrm{NaOH}$ concentrations ( $2 \mathrm{M}$ and $3 \mathrm{M}$ ) and different reaction times (5, 7 and 9 hours) to observe the effect of these variations on the composition of the produced Zeolite Y. The reaction temperature was, however, fixed at $80^{\circ} \mathrm{C}$. Table 2 presents the results of the XRF analysis of the synthesized Zeolite Y catalysts showing the composition of the major constituents. All the synthesized zeolite Y samples appear to have a significant silicon dioxide and aluminum oxide component with a relatively high iron oxide percentage. It can also be observed from Table 2 that the composition of $\mathrm{SiO}_{2}$ and $\mathrm{Al}_{2} \mathrm{O}_{3}$ compared to other constituents were generally higher across all samples. As shown in Table 2, the phenomenon also corresponds to the work carried out by Ariffin [11]. The highest composition of $\mathrm{SiO}_{2}$ reached was at $2 \mathrm{M}$ and 9 hours, suggesting that concentration and reaction time significantly affect the chemical composition of synthesized zeolite. 
TABLE 1: Chemical composition of PKSA and leached PKSA.

\begin{tabular}{lcc}
\hline Chemical constituent & PKSA (\%) & Treated PKSA (\%) \\
\hline $\mathrm{SiO}_{2}$ & 42.0 & 50.7 \\
$\mathrm{Al}_{2} \mathrm{O}_{3}$ & 6.9 & 4.6 \\
$\mathrm{Fe}_{2} \mathrm{O}_{3}$ & 2.5 & 0.3 \\
$\mathrm{MnO}$ & 0.3 & 0.6 \\
$\mathrm{CaO}$ & 12.0 & 14.1 \\
Others & 36.3 & 29.8 \\
\hline
\end{tabular}

Others include $\mathrm{P}_{2} \mathrm{O}_{5}, \mathrm{~K}_{2} \mathrm{O}, \mathrm{TiO}_{2}, \mathrm{MgO}$, and $\mathrm{Na}_{2} \mathrm{O}$.

TAble 2: Chemical Composition of Synthesized Zeolite Y under varying Conditions.

\begin{tabular}{lcccccc}
\hline Constituent & $\begin{array}{c}2 \mathrm{M} / 5 \\
\text { hours }\end{array}$ & $\begin{array}{c}2 \mathrm{M} / 7 \\
\text { hours }\end{array}$ & $\begin{array}{c}2 \mathrm{M} / 9 \\
\text { hours }\end{array}$ & $\begin{array}{c}3 \mathrm{M} / 5 \\
\text { hours }\end{array}$ & $\begin{array}{c}3 \mathrm{M} / 7 \\
\text { hours }\end{array}$ & $\begin{array}{c}3 \mathrm{M} / 9 \\
\text { hours }\end{array}$ \\
\hline $\mathrm{SiO}_{2}$ & 57.20 & 52.70 & 57.38 & 52.21 & 53.71 & 54.37 \\
$\mathrm{Al}_{2} \mathrm{O}_{3}$ & 23.20 & 30.95 & 23.22 & 28.60 & 30.94 & 28.35 \\
$\mathrm{Fe}_{2} \mathrm{O}_{3}$ & 0.03 & 0.20 & 0.03 & 0.02 & 0.20 & 0.03 \\
$\mathrm{MnO}$ & 0.14 & 0.08 & 0.12 & 0.11 & 0.02 & 0.07 \\
$\mathrm{CaO}$ & 6.15 & 8.12 & 6.18 & 9.45 & 8.15 & 7.22 \\
Others & 13.28 & 7.95 & 13.07 & 9.61 & 6.98 & 9.96 \\
\hline
\end{tabular}

Others include $\mathrm{P}_{2} \mathrm{O}_{5}, \mathrm{~K}_{2} \mathrm{O}, \mathrm{TiO}_{2}, \mathrm{MgO}$, and $\mathrm{Na}_{2} \mathrm{O}$. Values in percentage.

Measure of acidity. Generally, the acidity of a given catalyst is a measure of how fast a reaction can proceed in the catalyst's presence. Usually, zeolite catalysts experience chemical changes during cracking reactions, and as a result, their activity as a function of time becomes lower, hence the need for regeneration [24]. The Si/Al ratio of a zeolite catalyst usually determines its acidity. The acidity tends to increase in strength with an increasing $\mathrm{Si} / \mathrm{Al}$ ratio. Although the $\mathrm{Si} / \mathrm{Al}$ ratio increases, the cation concentration and ion exchange capacity decrease [32]. Table 3 shows the Si/Al ratio (SAR) of the starting material for zeolite synthesis and the synthesized zeolite samples. It can be observed from the table that the $\mathrm{Si} /$ $\mathrm{Al}$ ratio of the synthesized Zeolites was higher than the ratio for the treated ash.

Generally low (1-1.5 Si/Al ratio) and intermediate zeolites (2-5 Si/Al ratio) can comfortably remove water from organics and carry out separation and catalysis on dry streams. High zeolite (10-100 $\mathrm{Si} / \mathrm{Al}$ ratio) is hydrophobic can recover organics from the water stream and carry out separations and catalysis in the presence of water [32]. The $\mathrm{Si} / \mathrm{Al}$ ratio variation also produces differences in the $\mathrm{Si}-\mathrm{O}-\mathrm{Al}$ group's amount and distribution in their crystal structure. Hence, changes in the $\mathrm{Si} / \mathrm{Al}$ ratio result in the alteration of the zeolite crystal structure, which plays a significant role in determining zeolites' behavior or properties [33].

Although sample $2 \mathrm{M} / 80^{\circ} \mathrm{C} / 9$ hours has the most considerable value (2.18), samples $2 \mathrm{M} / 5$ hours, $3 \mathrm{M} / 5$ hours and $3 \mathrm{M} / 80^{\circ} \mathrm{C} / 9$ hours also fell within the range of $2-5$, which agrees with the literature value of intermediate zeolite $\mathrm{Y}$ catalyst [7]. The thermal and hydrothermal stabilities of zeolite are strongly related to its $\mathrm{Si} / \mathrm{Al}$ ratio. Hence these values depict that the synthesized zeolites have high thermal stability, which is required for a fluid catalytic cracking catalyst [34].
TABle 3: Si/Al ratio of Synthesized and Leached Samples.

\begin{tabular}{lc}
\hline Samples & $\mathrm{Si} / \mathrm{Al}$ \\
\hline $2 \mathrm{M} / 80 / 5$ hours & 2.16 \\
$2 \mathrm{M} / 80 / 7$ hours & 1.42 \\
$2 \mathrm{M} / 80 / 9$ hours & 2.18 \\
$3 \mathrm{M} / 80 / 5$ hours & 2.0 \\
$3 \mathrm{M} / 80 / 7$ hours & 1.42 \\
$3 \mathrm{M} / 80 / 9$ hours & 2.0 \\
Treated ash & 1.18 \\
\hline
\end{tabular}

3.2.2. SEM Analysis. Figure 2 shows the morphology of the treated palm ash and synthesized zeolite Y. Figure 2(b) depicts the underdeveloped zeolite Y crystals, which are gradually being formed. The underdeveloped nature of the zeolite crystals is attributed to the reaction conditions. This zeolite Y sample was initially synthesized using a reagent concentration of $2 \mathrm{M}$ and a reaction time of 9 hours. Increasing the aging time and concentration ( $3 \mathrm{M}$ and a reaction time of 9 hours) would promote a more defined structure, as seen in Figure 2(c). This representation presents a more defined crystal structure. It shows a complex three-dimensional, highly porous spongy crystalline zeolite, which agrees with a standardized zeolite $\mathrm{Y}$ catalyst [35]; Chindaprasirt et al. [36] and [25]. However, the crystals have a small surface area primarily due to a composite formed containing few zeolite crystals and non-crystallization palm kernel shells. It is also caused by the coalescence of neighboring micro-pores and pore capillaries' breakage in increased internal surface exposure [37-39]. The crystals' size could also mean insufficient aging time, resulting in the partial formation of crystalline zeolite Y.

3.2.3. Structural Analysis of Synthesized Zeolite Catalyst. In this section, the leaching process's structural effect and the alkaline hydrothermal treatment on the palm kernel ash were carried using computational processing of the scanning electron microscopy images. The 3D structural display of the background content, as shown in Figure 3, describes the tendencies of the cation exchange capacity of the material. The 3D structural display also determines the number of significant disjointed gaps, also known as grain size. Due to the higher grain size $(244 \mathrm{~nm})$ of the leached palm kernel ash compared to that of the synthesized zeolite $\mathrm{Y}$ catalyst $(209.334 \mathrm{~nm})$, it is believed to have more significant gaps in its structural formation within a thickness of $0.61 \mu \mathrm{m}$. The leached palm ash has a compact arrangement of its particles within a thickness of $0.24 \mu \mathrm{m}$, which means fewer structural formation gaps. The addition of sodium hydroxide also decreased the grain size by $14.3 \%$.

3.2.4. Fourier Transform Infrared Spectroscopy Analysis. An FTIR Spectrophotometer was used to show the vibrational spectroscopy of zeolite $\mathrm{Y}$, as observed in Figure 4 below. The spectra show strong IR absorption in the spectral region below $1200 \mathrm{~cm}^{-1}$. Vibration frequencies of the zeolite lattice result from stretching and bending modes of the T-O units. This is observed in the range 300 to $1300 \mathrm{~cm}^{-1}$ which indicates the presence of $\mathrm{SiO}_{4}$ or $\mathrm{AlO}_{4}$. The crystallization of 


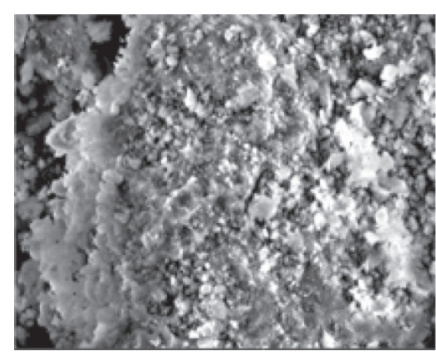

(a)

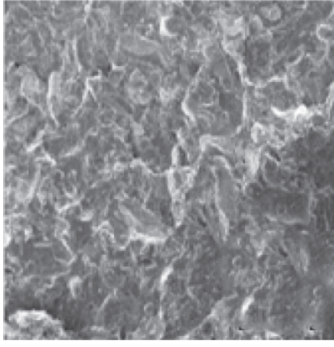

(b)

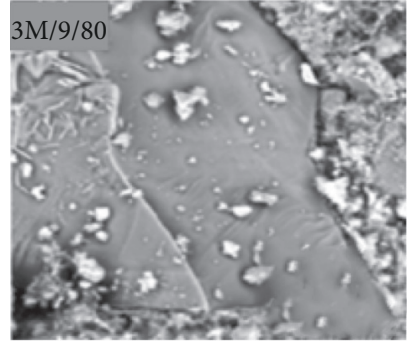

(c)

Figure 2: Representative SEM image of (a) Leached Palm Ash (b) Synthesized Zeolite Y IM/9 Hours (c) Synthesized Zeolite Y -3 M/9 Hours. All images were taken at a pressure of $70 \mathrm{pa}$, accelerating voltage of $15 \mathrm{kV}$, working distance of $10.8 \mathrm{~mm}$, lens magnitude of $15000 \mathrm{x}$, and horizontal field width of $124 \mu \mathrm{m}$.

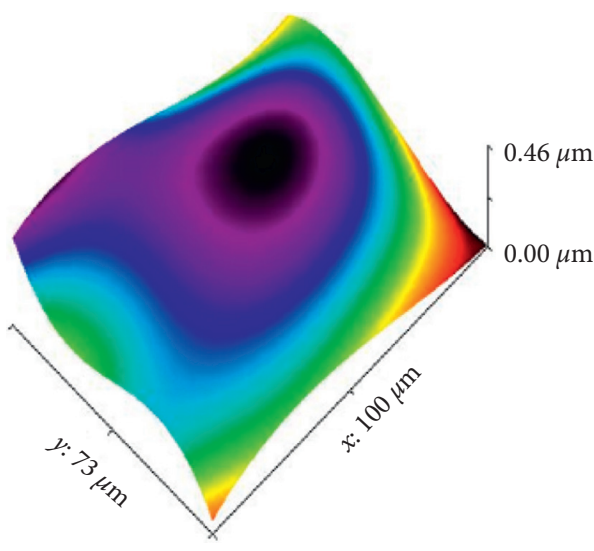

(a)

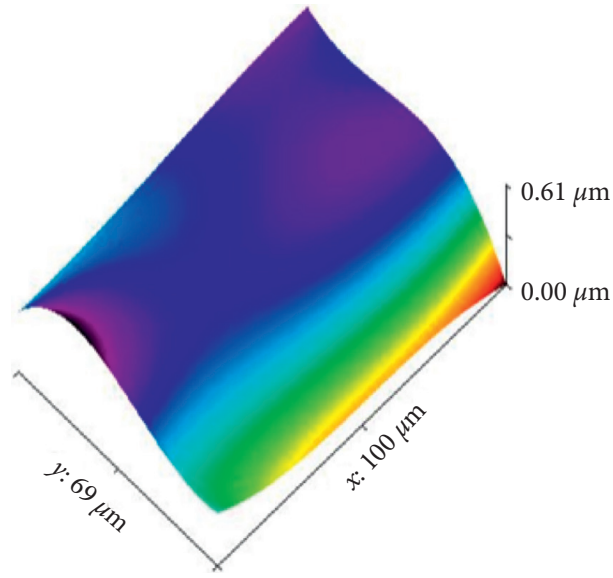

(b)

FIgURE 3: Structural analysis of (a) leached palm ash (b) synthesized zeolite Y.

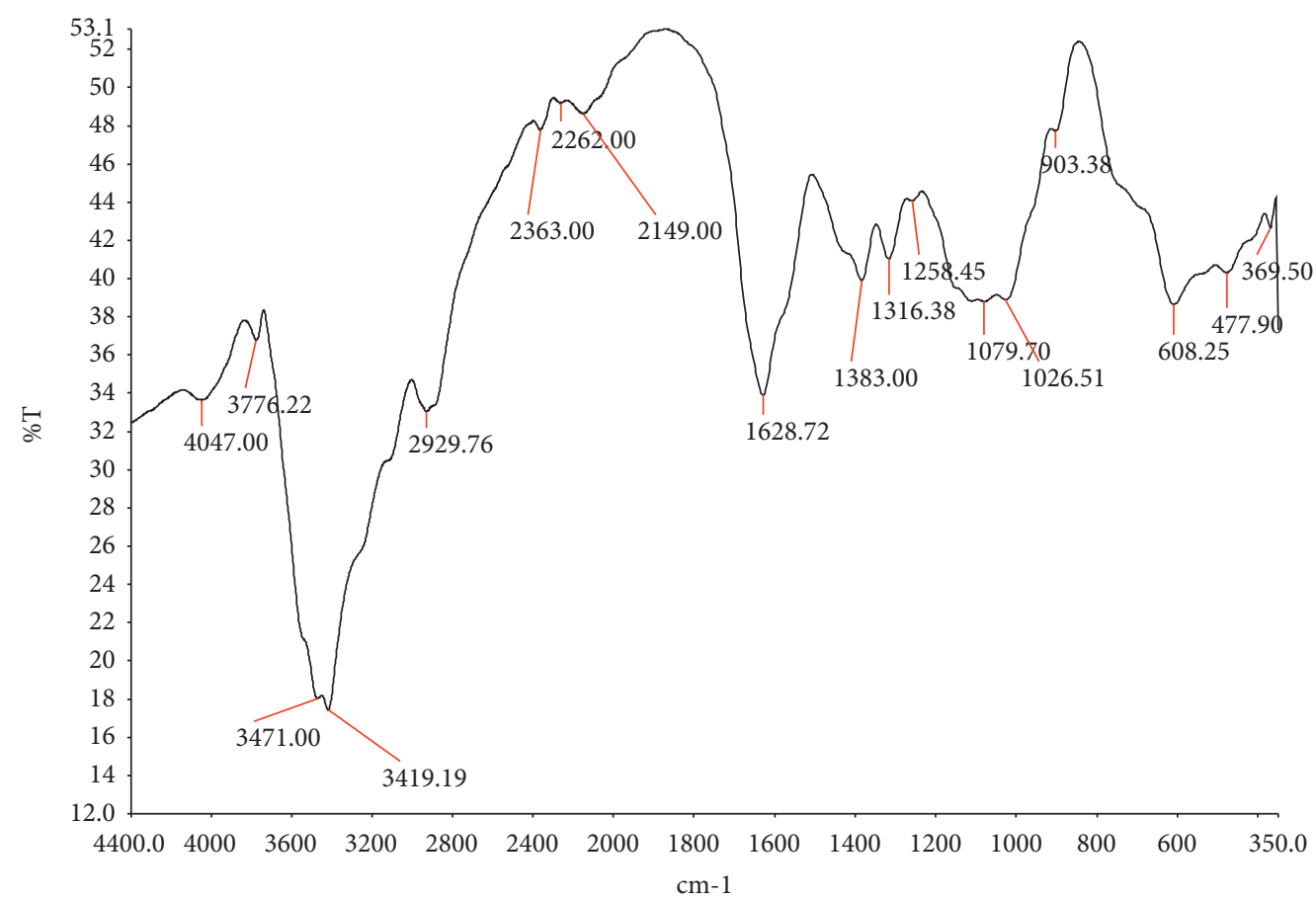

FIgURE 4: FTIR spectra of synthesized zeolite Y. 
pure zeolite $\mathrm{Y}$ using silica is favored at a temperature lower than $100^{\circ} \mathrm{C}$, with less $\mathrm{Na}_{2} \mathrm{O}$ or higher $\mathrm{SiO}_{2}$ content in the initial mixture. This is because zeolite $\mathrm{Y}$ is highly reactive due to the ability of its iron exchange forms to produce hydroxyl radicals from $\mathrm{H}_{2} \mathrm{O}_{2}$ [10]. $\mathrm{OH}$, bands are single intense bands occurring at approximately 3419 and $3471 \mathrm{~cm}^{-1}$, respectively.

These bands are accredited to the presence of hydroxyls in the faujasite super-cage. The faujasite super-cage usually consists of sodalite cages as its building block; hence its presence is depicted in the FTIR spectra [25, 35]. The FTIR spectrum also showed medium bands at $1628 \mathrm{~cm}^{-1}$. These bands can be attributed to the $\mathrm{H}_{2} \mathrm{O}$ deformation mode, usually seen at $1659 \mathrm{~cm}^{-1}$. The peak at about $1600 \mathrm{~cm}^{-1}$ points to water molecules, which shows that complete dehydration has not been achieved for the zeolite samples. The FTIR spectra of the synthesized Zeolite $\mathrm{Y}$ in this study are like those obtained from past works. [40, 41]. This further proves Zeolite Y's suitability synthesized from palm kernel shells to substitute commercial Zeolite Y catalysts in the FCCU. The impurities noticed are likely oxides, as shown in [31, 37, 39].

3.2.5. XRD Analysis. The XRD for the calcined palm kernel (PK) shell and the zeolite are presented in Figure 5. As shown in Figure 5 below, the prominent peaks that were present at $600^{\circ} \mathrm{C}$ for palm kernel ashes were muscovite (M), quartz $(\mathrm{Q})$, and hematite $(\mathrm{H})$. However, the quartz peaks showed a higher diffused pattern-an indication of high silicate content. Muscovite $\mathrm{kAl}_{2}\left(\mathrm{Si}_{3} \mathrm{AlO}_{10}\right)(\mathrm{OH})_{2}$ and hematite $\left(\mathrm{Fe}_{2} \mathrm{O}_{3}\right)$ also corresponds to data gotten from the $\mathrm{XRF}$ analysis. The peaks in the processed zeolite were found to correspond to the peaks of the quartz and hematite. It was observed that an unnamed peak in the calcined PK shell corresponds to one of the peaks in the zeolite. This unnamed peak may be impurity inherent in the palm kernel shell. The crystallographic information shows that the crystallinity of zeolite lies on planes (331), (533), (642), (664), and (840). The merged peaks of zeolite and quartz at (511) and (642) show that the raw material's crystallinity is almost unaltered despite the treatment. Therefore, the XRD result corroborated the high silicon content, as shown in Table 1.

3.2.6. Textural Properties of Synthesized Zeolite Y Catalyst and the Effect of Reagent Concentration and Reaction Time on Meso-Porosity of Synthesized Zeolite Y Catalyst. The volume filling of available micro-pores occurs because of the pore size's commensurability with the nitrogen molecules [42]. From Figure 6, it is observed that the isotherms of treated PKSA, $2 \mathrm{M} / 7 / 80,2 \mathrm{M} / 5 / 80$, and $3 \mathrm{M} / 9 / 80$ is a combination of types II and I adsorption Isotherms accompanied by a prominent hysteresis of type $\mathrm{H} 4$ (according to the IUPAC classification of hysteresis loops) in between the region $0.04-0.08 \mathrm{P} / \mathrm{Po}$. The isotherms and

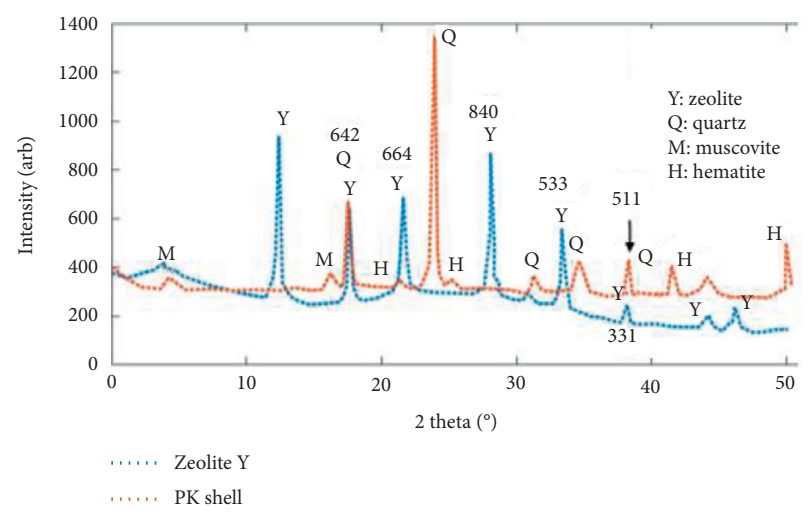

FIGURE 5: XRD for calcined palm kernel shell and zeolite.

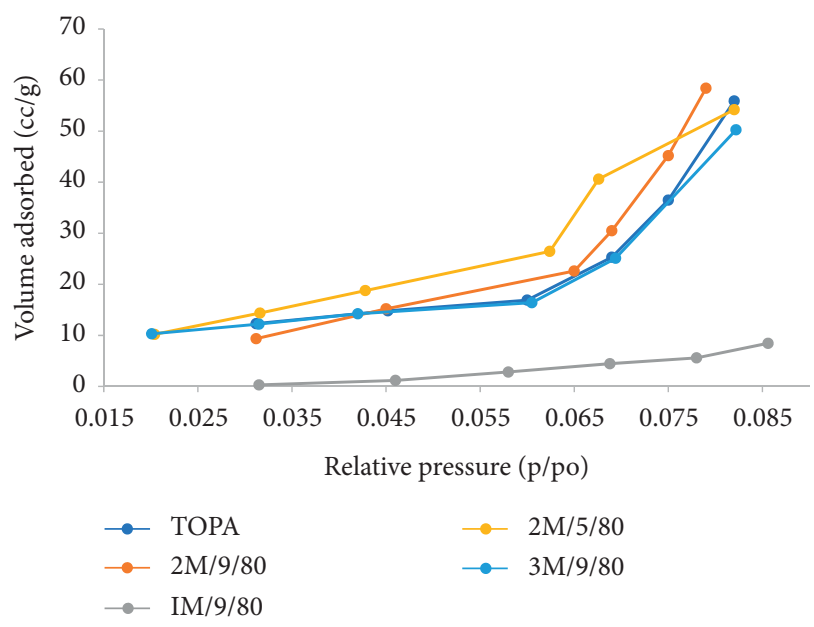

FIGURE 6: Relative pressure versus volume adsorbed for synthesized zeolite Y samples.

relative pressure values fall within standards for zeolite $\mathrm{Y}$ catalyst, as Yates [43] highlighted. These values also indicate a higher level of mesoporosity when compared to $1 \mathrm{M} / 9 / 80$. These differences are primarily due to the nature of raw materials and the differences in treatment parameters [44].

These micro-pores are associated with the pore deepening mechanism, resulting in the steady increase of Brunauer-Emmett-Teller (BET) specific surface areas. The void fraction constitutes these micro-pores between graphitic layers with the restricted diameter, as shown in Figure 7. The specific surface areas of the samples were determined from $\mathrm{N} 2$ adsorption isotherms using a BET method. These values fall within the range of $80-260 \mathrm{~m}^{2} / \mathrm{g}$, which remains a prominent characteristic of mesostructured Zeolite Y catalyst [45]. Although the BET surface area is a useful indication; however, it should not be regarded as the actual surface area of a highly microporous material [46]. 


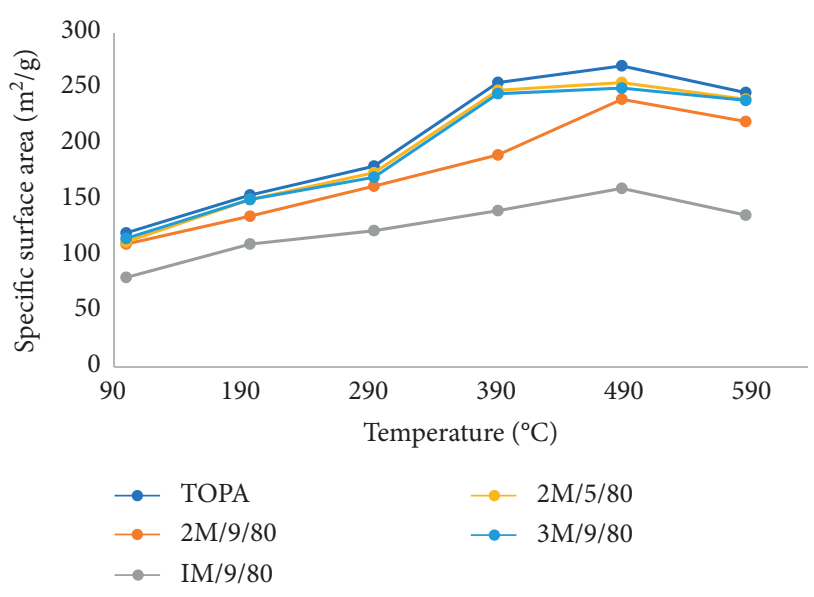

Figure 7: Temperature versus specific surface area for synthesized zeolite Y samples.

\section{Conclusion}

A spongy, porous zeolite crystal was formed with the presence of hydroxyls in its sodalite cage. All samples had a combination of types II \& I adsorption isotherms, $\mathrm{Si} / \mathrm{Al}$ ratio of $2-5$, and specific surface area within $80-260 \mathrm{~m}^{2} / \mathrm{g}$, which indicates the presence of intermediate mesostructured Zeolite Y catalyst. FTIR highlighted the significant functional groups present in the novel compound, which proves its suitability for use in a fluid catalytic cracking unit.

\section{Data Availability}

Included within the article.

\section{Conflicts of Interest}

The authors declare that they have no conflicts of interest.

\section{Acknowledgments}

The authors want to express gratitude to the management of Covenant University, Nigeria, for providing an enabling environment for this research.

\section{References}

[1] A. O. Mamudu, E. Okonkwo, S. I. Okocha, E. E. Okoro, F. Elehinafe, and K. Igwilo, "The design of an integrated crude oil distillation column with submerged combustion technology," The Open Chemical Engineering Journal, vol. 13, no. 1, pp. 7-22, 2019.

[2] S. Haridoss, "A study on the role of catalysts used in catalytic cracking process in petroleum refining," International Journal of Chemistry, vol. 10, no. 7, pp. 79-86, 2017.

[3] M. E. Emetere, O. A. Mamudu, F. Ishola, D. Lawal, F. B. Elehinafe, and A. Odunayo, "The production of the matrix component of the fluid catalytic cracking unit from watermelon peel," International Journal of Engineering and Technical Research, vol. 9, no. 5, pp. 1259-1262, 2020.

[4] M. A. Fahim, T. A. Alsahhaf, and A. Elkilani, Product Blending in Fundamentals of Petroleum Refining, pp. 237-261, Elsevier, Amsterdam, Netherlands, 2010.
[5] E. T. C. Vogt and B. M. Weckhuysen, "Fluid catalytic cracking: recent developments on the grand old lady of zeolite catalysis," Chemical Society Reviews, vol. 44, no. 20, p. 7342, 2015.

[6] R. M. Barrer, Hydrothermal Chemistry of Zeolites, p. 360, Academic Press, New York, NY, USA, 1982.

[7] Z. Liu, C. Shi, D. Wu, S. He, and B. Ren, "A simple method of preparation of high silica zeolite $\mathrm{Y}$ and its performance in the catalytic cracking of cumene," Journal of Nanotechnology, vol. 2016, no. 7, pp. 1-6, 2016.

[8] W. Vermeiren and J.-P. Gilson, "Impact of zeolites on the petroleum and petrochemical industry," Topics in Catalysis, vol. 52, no. 9, pp. 1131-1161, 2009.

[9] Y. Yaping, Z. Xiaoqiang, Q. Weilan, and W. Mingwen, "Synthesis of pure zeolites from supersaturated silicon and aluminum alkali extracts from fused coal fly ash," Fuel, vol. 87, no. 10-11, pp. 1880-1886, 2008.

[10] M. M. Rahman and N. Hasnida, "Preparation of zeolite Y using local raw material rice husk as a silica source," Journal of Scientific Research, vol. 1, no. 2, pp. 285-291, 2009.

[11] B. A. Ariffin, "Production of zeolites from oil palm ash," Bachelor of Chemical Engineering Thesis, Universiti Malaysia Pahang, Gambang, Malaysia, 2010.

[12] C. P. Faizul, C. Abdullah, and B. Fazlul, "Extraction of silica from palm ash via citric acid," Advances In Environmental Biology, vol. 795, no. 12, pp. 3690-3695, 2013.

[13] F. Ishola, O. Towoju, A. Mamudu, O. Olatunji, S. Akinlabi, and J. Oladejo, "Nigerian oil palm industry as a sustainable renewable energy resource," in E3S Web of Conferencesvol. 152, p. 02005, EDP Sciences, Les Ulis, France, 2020.

[14] F. Ishola, F. A. Oyawale, A. O. Inegbenebor, and H. O. Boyo, "Design of a high-temperature anaerobic gas-furnace suitable for pyrolysis," IOP Conference Series Material Science Engineering, vol. 413, 2018.

[15] N. Sabzoi, S. Siddhartha, A. Saadia, S. A. Brahim, and A. S. Muhammad, "A critical analysis on palm kernel shell from oil palm industry as a feedstock for solid char production," Reviews in Chemical Engineering, vol. 32, no. 5, pp. 489-505, 2016, eISSN 2191-0235, ISSN 0167-8299.

[16] J. Cejka, A. Corma, and S. Zone, Zeolites and Catalysis: Synthesis, Reactions, and Applications, Wiley-VCH, Weinheim, Germany, 2010.

[17] S. Gonthier and R. W. Thompson, "Effects of seeding on zeolite crystallisation, and the growth behavior of seeds," Advanced Zeolite Science and Applications, vol. 85, pp. 43-73, 1994.

[18] Alibaba.com, Zeolite Y Catalyst, Alibaba.com, Hangzhou, China, 2020, https://www.alibaba.com/showroom/zeolite+y+catalyst. html?fsb=y\&IndexArea=product_en\&CatId=\&SearchText=zeolit $\mathrm{e}+\mathrm{y}+$ catalyst\&isGalleryList $=\mathrm{G}$.

[19] J. Adeoye, J. A. Omoleye, and M. A. Ojewumi, "Synthesis of zeolite Y from kaolin using novel method of dealumination," International Journal of Applied Engineering Research, vol. 12, no. 5, pp. 755-760, 2017.

[20] C. Faizul and C. Abdullah, "Zeolite synthesis from oil palm ash using hydrothermal treatment," Advanced Materials Engineering and Technology AIP Conference Proceedings, vol. 1835, Article ID 020016, 2017.

[21] C. P. Faizul, C. Abdullah, and B. Fazlul, "Synthesis of zeolites from treated oil palm ash," Applied Mechanics and Materials, vol. 754-755, pp. 1035-1039, 2015.

[22] S. R. Pouya, H. Shafaghat, and M. A. Wan, "Aromatic hydrocarbon production by catalytic pyrolysis of palm kernel shell waste using a Bi-functional Fe/HBeta catalyst: effect of 
lignin derived phenolics on zeolite deactivation," Green Chemistry, vol. 18, no. 6, pp. 1684-1693, 2016.

[23] Y. Prawiyanto, A. Shofiyani, and T. A. Zaharah, "Synthesis and characterization of zeolite materials from power plant fly ash," Asian Journal of Chemistry, vol. 30, no. 5, pp. 993-997, 2018.

[24] N. Salahudeen and A. S. Ahmed, "Synthesis of hexagonal zeolite Y from Kankara kaolin using a split technique," Journal of Inclusion Phenomena and Macrocyclic Chemistry, vol. 87, no. 1-2, p. 149, 2016.

[25] V. S. Somerset, L. F. Petrik, R. A. White, M. J. Klink, D. Key, and E. I. Iwuoha, "Alkaline hydrothermal zeolites synthesized from high $\mathrm{SiO} 2$ and $\mathrm{Al} 2 \mathrm{O} 3$ co-disposal fly ash filtrates," Fuel, vol. 84, no. 18, pp. 2324-2329, 2005.

[26] W. K. Sung, S. K. Bon, and H. L. Dong, "Catalytic pyrolysis of palm kernel shell waste in a fluidised bed," Bioresource Technology, vol. 167C, pp. 425-432, 2014.

[27] Y. Zarina, A. M. MustafaAl Bakri, H. Kamarudin, I. Khairul Nizar, and A. R. Rafiza, "Review on the various ash from palm oil waste as geopolymer material," Reviews on Advanced Material Science, vol. 34, pp. 37-43, 2013.

[28] R. Mallada, "Hydrothermal synthesis of zeolite," in Encyclopedia of Membranes, E. Drioli and L. Giorno, Eds., Springer, Berlin, Germany, 2014.

[29] S. Brunauer, P. H. Emmett, and E. Teller, "Adsorption of gases in multimolecular layers," Journal of the American Chemical Society, vol. 60, no. 2, pp. 309-319, 1938.

[30] B. Y. Lim, S. Husseinsyah, and P. L. Teh, "A study on the rheological properties of low-density polyethylene/palm kernel shell composites," Advanced Materials Research, vol. 626, pp. 615-619, 2012.

[31] A. L. Iskander, E. M. Khald, and A. S. Sheta, "Zinc and manganese sorption behavior by natural zeolite and bentonite," Annals of Agricultural Sciences, vol. 56, no. 1, pp. 43-48, 2011.

[32] E. M. Flanigen, R. W. Broach, and S. T. Wilson, Zeolites in Industrial Separation and Catalysis, WILEY-VCH, Weinheim, Germany, 2010, ISBN: 978-3-527-32505-4.

[33] M. W. Munthali, A. E. Mohammed, E. Johan, and N. Matsue, "Proton adsorption selectivity of zeolites in aqueous media: effect of Si/Al ratio of zeolites," Molecules, vol. 19, pp. 20468-20481, 2014.

[34] R. Wan Nik, Fluid Catalytic Cracking Handbookpp. 87-115, Butterworth-Heinemann, Oxford, UK, Third edition, 2012.

[35] M. A. Keane, "Catalytic processing of waste polymer composites," Management, Recycling And Re-Use Of Waste Composites, pp. 122-151, Woodhead Publishing Series, Amsterdam, Netherlands, 2010.

[36] P. Chindaprasit, R. Kanchancha, A. Sathonsaowaphak, and H. T. Cao, "Sulfate resistance of blended cements containing flyash and rice husk ash," Construction and Building Materials, vol. 21, pp. 1356-1367, 2007.

[37] J. Guo and Z. Ji, "Superhydrophilic ZSM-5 zeolite-coated membrane for enhancing water coalescence in water-in-oil emulsions," Colloids and Surfaces A: Physicochemical and Engineering Aspects, vol. 595, p. 124727, 2020.

[38] S. M. Mak, B. T. Tey, K. Y. Cheah, W. L. Siew, and K. K. Tan, "The effect of mechanical grinding on the mesoporosity of steam-activated palm kernel shell activated carbons," Journal of Chemical Technology \& Biotechnology, vol. 84, no. 9, pp. 1405-1411, 2009.

[39] X. Wang, W. Liu, and Q. Huang, "Simultaneously demulsification and coalescence deoiling of $\mathrm{O} / \mathrm{W}$ emulsion by a zeolite composite material," Chemical Engineering and Processing-Process Intensification, vol. 153, p. 107954, 2020.

[40] N. S. Ahmedzeki and B. A. Al-tabbakh, "Synthesis and characterisation of nano-crystalline zeolite Y," Al-Khwarizmi Engineering Journal, vol. 12, no. 1, pp. 78-79, 2016.

[41] N. Taufiqurrahmi, A. R. Mohamed, and S. Bhatia, "Nanocrystalline zeolite Y: synthesis and characterisation," IOP Conference Series: Materials Science and Engineering, vol. 12, 2011.

[42] N. Yalcin and V. Sevinc, "Studies of the surface area and porosity of activated carbons prepared from rice husks," Carbon, vol. 38, pp. 1943-1945, 2000.

[43] D. J. C. Yates, "Studies on the surface area of zeolites as determined by physical adsorption and X-ray crystallography," Canadian Journal of Chemistry, vol. 46, p. 1965, 1968.

[44] M. Greenbank and S. Sports, "Effects of starting material on activated carbon characteristics and performance," Information Bulletin IB-1017-06/95, pp. 1-13, Calgon Corporation, Pittsburgh, PA, USA, 1995.

[45] J. G. Martinez, M. Johnson, J. Valla, K. Li, and J. Y. Ying, "Mesostructured zeolite Y-high hydrothermal stability and superior FCC catalytic performance," Catalysis Science \& Technology, vol. 2, no. 5, pp. 987-994, 2012.

[46] K. S. W. Sing, D. H. Everett, R. A. W. Haul, L. Moscou, R. A. Pierotti, and J. Rouquerol, "Reporting physisorption data for gas/solid systems with special reference to the determination of surface area and porosity (Recommendations 1984)," Pure and Applied Chemistry, vol. 57, no. 4, pp. 603-619, 1985. 